\title{
A Review on the Performance Analysis of Engine Bracket
}

\author{
Shiv Kumar Pandit \\ M. Tech. Scholar \\ NRI Group of Institutions, Bhopal \\ India \\ ashishshrivastava3437@gmail.com
}

\author{
Ashish Shrivastava \\ Assistant Professor \\ NRI Group of Institutions, Bhopal \\ India \\ shivpandit0121@gmail.com
}

\begin{abstract}
Engine mounts have an important function of containing firmly the power-train components of a vehicle. Correct geometry and positioning of the mount brackets on the chassis ensure a good ride quality and performance. As an FSAE car intends to be a high performance vehicle, the brackets on the frame that support the engine undergo high static and dynamic stresses as well as huge amount of vibrations. Hence, dissipating the vibrational energy and keeping the stresses under a pre-determined level of safety have been achieved by careful designing and analysis of the mount brackets.
\end{abstract}

Keyword: Modal Analysis; Static Analysis; Optimization; Mounting Bracket; Hyper mesh, Optistruct.

\section{INTRODUCTION}

In an automotive vehicle, the engine rests on brackets which are connected to the main-frame or the skeleton of the car. Hence, during its operation, the undesired vibrations generated by the engine and road roughness can get directly transmitted to the frame through the brackets. This may cause discomfort to the passenger or might even damage the chassis. When the operating frequency or disturbance approaches the natural frequency of a body, the amplitude of Vibrations gets magnified. The first and the foremost function of an engine mounting bracket is to properly balance (mount) the power pack (engine \& transmission) on the vehicle chassis for good motion control as well as good isolation.

The need for light weight structural materials in automotive applications is increasing as the pressure for improvement in emissions and fuel economy increases. The most effective way of increasing automobile mileage while decreasing emissions is to reduce vehicle weight. The strong emphasis on the cost has demanded the component manufacturers to improve the performance of their materials and to find the methods to deliver these materials at reduced cost[3]. There are a number of noise and vibration sources that affect the vehicle body. The noise and vibration occur because the power that is delivered through bumpy roads, the engine, and suspension result in the resonance effect in a broad frequency band. The ride and noise characteristics of a vehicle are significantly affected by vibration transferred to the body through the chassis mounting points from the engine and suspension. Vibration damping can be either provided by using separate dampers or by suitably deciding the material and dimensions of the brackets. Moreover, the brackets also undergo deflection under static and dynamic loads.

The mounting system is the primary interface between the power train and the frame therefore, it's vital to the determination of the vibration isolation characteristics. There are two major problems that engineers must deal with when it comes to vibration isolation. The first problem is force isolation, which is frequently encountered in rotating or reciprocating machinery with unbalanced masses. The main objective in this problem is to minimize the force transmitted from the machine to the supporting foundation. The second problem is motion isolation. This is broadly achieved by mounting equipment on a resilient support or an isolator such that the natural frequency of the equipment-support system is lower than the frequency of the incoming vibrations to be 
isolated. The natural frequency of the mounting system should be lower than the engine disturbance frequency to avoid the excitation of the mounting system resonance. This will ensure a low transmissibility. In diesel engines the engine mounting is one of the major problems. Due to the Un-throttled condition, and higher compression ratio of the diesel engine, the speed irregularities particularly at low Speed and Low load conditions and are significantly higher than gasoline engines. By optimizing the thickness and shape of major mounting points made it possible to design a vehicle with optimized weight and performance at initial designing stages.

\section{LITERATURE REVIEW}

A.S.Adkine et al. [1] This current paper accounts for the investigation of engine mounting bracket by using ANSYS. Static and modal analysis of engine mounting bracket was done in order to investigate whether the current natural frequency of engine mounting bracket is lower than that of self-excitation frequency of bracket. The obtained results were also examined for cross section of bracket. It was found that circular cross section having stress induced $128.47 \mathrm{MPa}$ is more reliable than square cross section. The results were analyzed for stresses and deformations. The design was tested for different materials like Magnesium, ERW-1 and ERW-3 along with suitability of material. Stresses induced in magnesium bracket were $64.07 \mathrm{MPa}$ with the deformation of $1.20 \mathrm{~mm}$. It can be anticipated that magnesium brackets are corrosion resistant and can be considered for desired application.

Jasvir Singh Dhillon et.al [2] Engine mounts have an important function of containing firmly the power-train components of a vehicle. Correct geometry and positioning of the mount brackets on the chassis ensures a good ride quality and performance. As an FSAE car intends to be a high performance vehicle, the brackets on the frame that support the engine undergo high static and dynamic stresses as well as huge amount of vibrations. Hence, dissipating the vibrational energy and keeping the stresses under a pre-determined level of safety should be achieved by careful designing and analysis of the mount brackets. Keeping this in mind the current paper discusses the modeling, Finite Element Analysis, Modal analysis and mass optimization of engine mount brackets for a FSAE car. As the brackets tend to undergo continuous vibrations and varying stresses, the fatigue strength and durability calculations also have been done to ensure engine safety.

Sebastian C S et.al [3] The study of a jet engine mounts by FEA usually deals with the stress analysis of the mount, a very few papers deal with the displacement analysis. It is futile to believe that mounts that only stress analysis is necessary, as the displacement of the mount (elongation) is also an important factor when real life scenarios come into play. For the study the mount was designed using CATIA V5 and was analyzed using ANSYS. The ends that were to be fixed onto the chassis were fixed and then suitable load of $1000 \mathrm{~N}$ was applied to the load bearing region. Study was initially done using $\mathrm{Al}$ alloy and $\mathrm{Mg}$ as materials and then titanium alloy (Ti $6 \mathrm{Al} 4 \mathrm{~V}$ ) was also used on the final model. The initial models had a stress in the range of 10 and displacement was in the range of 20-30 meters which was unacceptable and suitable modification were made to the model in geometry and its dimensions so as to reach the optimal value of $5 \mathrm{~mm}$ displacement and stress of $2.5 \mathrm{KN}$ for $\mathrm{Al}$ and $10 \mathrm{~mm}$ displacement and $3 \mathrm{KN}$ stress for $\mathrm{Mg}$ alloy. Later the study was done using Titanium alloy (Ti 6Al $4 \mathrm{~V})$ and it is seen that the stresses and displacement were well within the permissible limit .From the study it is very evident that of all materials Titanium alloy had the minimal deviation from ideal behavior, and it is safe to assume that Titanium alloy ( $\mathrm{Ti} 6 \mathrm{Al} 4 \mathrm{~V}$ ) is the most suited alloy to make engine mounts.

Amol S Adkine et al. [4] n this work an attempt was made to analyse the engine mounting bracket. Design includes the modelling of the engine mounting brackets by taking into account all packaging constraints. Analysis includes Static Analysis of engine mounting bracket. The main purpose of this study is to examine the natural frequency of by analytically and through developing the model and self-excitation frequency of engine bracket. An attempt was made to check whether the natural frequency of engine mounting bracket is less than self-excitation frequency of engine bracket. Hence this work is carried by using ERW-1, ERW-2, aluminum and magnesium alloys for the engine mount bracket. The results are analyzed for stresses and deformations.

Vaibhav S Kathavate et al. [5] In this work an attempt was made to analyse the engine mounting bracket. Design includes the modelling of the engine mounting brackets by taking into account all packaging constraints. Analysis 
includes Static and Dynamic Analysis of engine mounting bracket. The main purpose of this study is to examine the natural frequency of by analytically and through developing the model and self-excitation frequency of engine bracket. An attempt was made to check whether the natural frequency of engine mounting bracket is less than self-excitation frequency of engine bracket. Hence this work is carried by using ERW-1, ERW-2, aluminum and magnesium alloys for the engine mount bracket. The results are analysed for stresses and deformations. Key Words: ANSYS, static structure, ERW-1 steels, ERW-2 steels.

\section{PROPOSED METHODOLOGY}

1) Static structural Analysis is the analysis in which displacements, stresses, strains and forces on structure or a component due to load distribution can be find out.

2) Modal Analysis of engine mounting bracket to determine whether the current design has a natural frequency which is lower than the excitation frequency.

3) Shape Optimization The design will be changed by changing the cross section i.e. square cross section to circular cross section.

4) Material Optimization the design will be tested for different materials, ERW-2, Aluminums, and magnesium and suitability of material will be tested.

5) Study the effect of seam weld on engine mounting bracket.

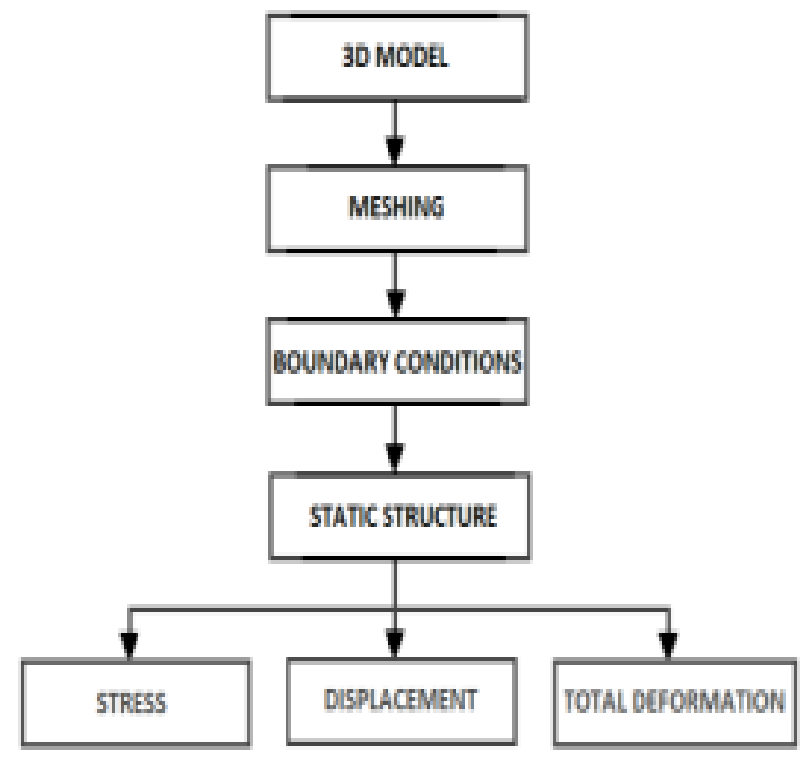

Figure 1: Flow chart for Static Structural analysis

\section{FINITE ELEMENT ANALYSIS:}

Finite Element Analysis is a mathematical representation of a physical system comprising a part/assembly (model), material properties, and applicable boundary conditions (collectively referred to as pre-processing), the solution of that mathematical representation (solving), and the study of results of that solution (post-processing). Simple shapes and simple problems can be, and often are, done by hand. Most real world parts and assemblies are far too complex to do accurately, let alone quickly, without use of a computer and appropriate analysis software. The numerical technique has advantages of experimental as well as analytical method. This analysis requires less resources compared to that of experimental methods. Finite element analysis (FEA) is a powerful engineering tool that can solve many kinds of engineering problems to as high degree of precision as necessary. In essence, the finite element is a mathematical method for solving ordinary \& partial differential equations. FEM is a computational technique used to obtain approximate solutions of boundary value problems in Engineering. This involves deciding what parts are important and what unnecessary detail can be omitted i.e. disregard any small geometric irregularities; consider load as concentrated, homogenized composite material properties. Then we choose the theory which best describes the behavior of the model such as the behavior best described by beam theory, plate bending theory, plane elasticity, plane strain or plane stress formulations.

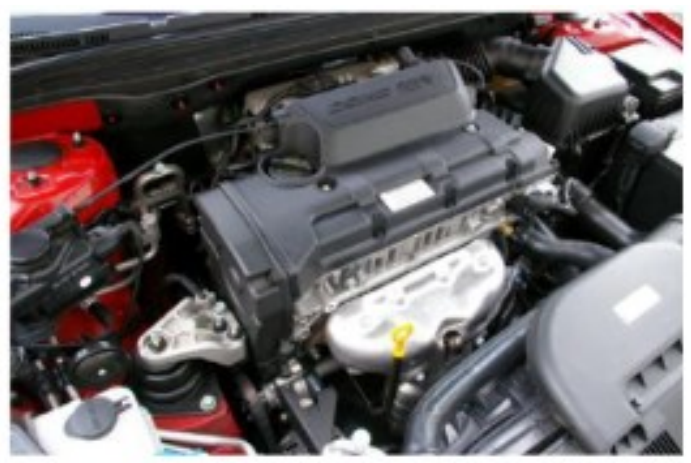

Figure 2: location of engine mounting bracket 


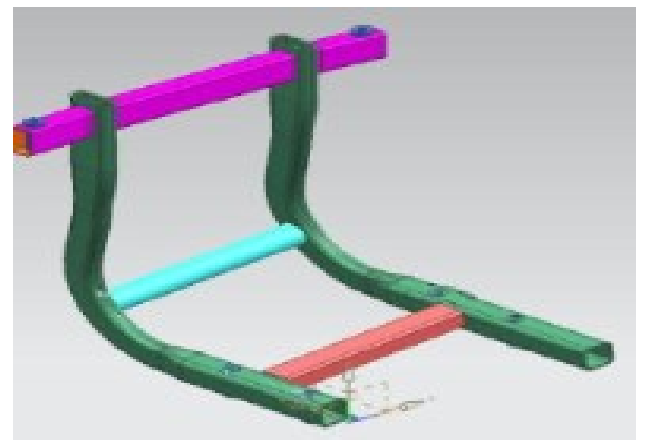

Figure 3: Isometric view of the mounting bracket

\section{CONCLUSION}

The major role of the mounting system in addition to physically mount the powertrain to the vehicle frame is to provide vibration isolation. It is important to insure sufficient clearance between the powertrain and the surrounding components. The design is achieved by imposing the mounting system. The mounting system should be able to isolate the frame under steady state loading conditions at the same time limiting the maximum excursion of the powertrain under transient loading conditions.

\section{REFERENCES}

[1] A.S.Adkine, G P Overikar ".Design And Analysis Of Engine Mounting Bracket Using Ansys Tool" International Journal of Innovation in Engineering, Research and Technology [IJIERT] 2016.

[2] Jasvir Singh Dhillon, Vikram Sawant "Design of Engine Mount Bracket for a FSAE Car Using Finite Element Analysis" Int. Journal of Engineering Research and Applications.2015

[3] Sebastian C S, "Design and Optimization of Engine Mount Bracket" International Journal of Application or Innovation in Engineering \& Management (IJAIEM) 2016.

[4] Amol S Adkine, Vaibhav S Kathavate "Static Behaviour of Engine Mounting Bracket” DOI: 10.17148/IARJSET.2015.2416 May 2015

[5] Vaibhav S Kathavate, Amol S Adkine "Optimization In Design Parameters Of Engine Mounting Bracket” March 2015

[6] Sahil Naghate, Sandeep Patil, "Modal Analysis Of Engine Mounting Bracket Using FEA", International Journal of Engineering Research and Applications (IJERA), Vol. 2. Issue4. July-August-2012,pp.1973-1979.

[7] Koushik S.," Static and Vibration Analysis of Engine mounting Bracket of TMX-20-2 using OptiStruct", Altair Technology Conference, India -2013. 